\section{Ideal practice handpiece cover}

B.A. International, certified to EN ISO 13485:2016 (quality management system for medical devices) now allows for costeffective budgeting of dental practices' handpieces exactly to the customer's requirements and without hassle.

Choose the handpieces required, add a maintenance pack which gives the monthly oil and bespoke laser marking and the customer is ready to go. For 36 months, all a customer's handpiece related costs are then fully covered and paid for, excluding accidental damage and evidenced lack of care and maintenance.

BA Total Care turbines come from as little as $£ 12.76+$ VAT per month. The whole package is financed through a low cost $1.45 \%$ finance offer, and after 36 months, the customer has the opportunity to trade the handpieces in or purchase them outright for a nominal sum.

For more information, contact B.A. International on 01604777700 or its exclusive distributors Henry Schein Dental or Kent Express.

\section{Two major breakthroughs in composite technology}

Two breakthroughs in composite technology have been reported by Trycare which the company says have been made with the dentist and the patient in mind.

Firstly, Tokuyama have grown 'aesthetic pearl fillers' where others use 'broken rocks'. Supra-nano Spherical Filler is produced using the sol-gel method. This allows Tokuyama to grow spheres of specific translucency, colour, size and refractive index for optimal optical and physical performance. Other composites are made from blocks of filler that are randomly ground, thereby compromising the product.

The second breakthrough is that RAP has accelerated curing that gives extended working time with 10 second light cure.

In conventional light curing, camphorquinone (CQ) catalyst generates one energised monomer each reactive cycle. Tokuyama's innovative initiator system energises several monomer molecules each reactive cycle. The benefit is that less CQ gives a longer working time and the ability to energise lots of monomer with a short cure time.

The benefits are extended working time; quick curing time; superb, fast, long lasting polish; exceptional handling; superior blend and shade matching; and minimal shrinkage after light curing (1.3\% linear).

Call 01274885544 for a free trial experience, or visit www.trycare. co.uk/tokuyama.

\section{ADI Team Congress 2019 - Speakers announced}

The ADI Team Congress 2019 will be a highlight of the educational calendar next year, offering a unique learning opportunity for all members of the dental team.

The event, entitled 'Shaping the Future of Dental Implantology: Techniques - Technology - Teamwork' takes place on 2-4 May 2019 at the Edinburgh International Conference Centre (EICC) in Edinburgh.

Internationally renowned speakers on the plenary programme are:

- Istvan Urban - Hungary

- Lyndon F Cooper - USA

- Mark Montana - USA

- Alessandro Agnini - Italy

- Andrea Agnini - Italy

- Markus B Blatz - USA

- Tord Berglundh - Sweden

- Wael Att - Germany

- Anabell Bologna - Venezuela

- Barry P Levin - USA

- John E Davies - Canada

- Markus B Hürzeler - Germany

- Craig M Misch - USA

- Daniele Cardaropoli - Italy

- David Guichet - USA.

The exciting lecture programme will cover topics including advances in regeneration and implant design, hard and soft tissue management, surgical veneer grafts and vertical augmentation.

To book a place, visit www.adi.org.uk/congress 19 .

\section{Finding the perfect match}

Specialist agency Dental Elite says that running a successful dental practice and treating patients to the very highest of standards takes time and dedication.

Therefore, recruiting a new member to the team can be time consuming, complex and can take a dentist away from daily responsibilities.

However, it is a crucial task that needs to have resources dedicated to it to minimise the risk of a poorly fitting individual to the team. Working with an agency, such as Dental Elite, means that a recruitment strategy can be put in place to find the best talent to suit the role and the team, in the most efficient way.

Whether the position is in a single-handed practice or a larger group, for a receptionist or practice manager, or in a temporary or permanent role, Dental Elite has contacts with a pool of talent ready to seize a new challenge.

The company invites dentists to take the pressure off by removing a task from their 'to do' list by working with a company that will carry out the advertising, screening and selection process to find that perfect match.

For more information on Dental Elite, visit www.dentalelite. co.uk, email info@dentalelite.co.uk or call 01788545900. 